\title{
SAR Processing Algorithm with Built-In Geometric Correction
}

\author{
O. O. Bezvesilniy, I. M. Gorovyi, S. V. Sosnytskiy, V. V. Vynogradov, and D. M. Vavriv \\ Institute of Radio Astronomy, National Academy of Sciences of Ukraine \\ 4, Chervonopraporna St., Kharkiv, 61002, Ukraine \\ E-mail:vavriv@rian.kharkov.ua
}

\section{Received October 11, 2010}

Synthetic aperture radar (SAR) systems onboard small aircrafts suffer from trajectory deviations and instabilities of antenna orientation. These kinds of motion errors lead to significant geometric distortions in SAR images. In order to correct the distortions, we propose a time-domain multi-look stripmap SAR processing algorithm with built-in geometric correction. In the algorithm, the azimuth reference functions and range migration curves are designed to produce SAR images directly on a correct rectangular grid on the ground plane. The proposed technique has been successfully tested by using a Ku-band airborne SAR system installed onboard light-weight aircraft.

Keywords: synthetic aperture radar, airborne SAR, geometric distortions, multi-look processing, motion error compensation

\section{Introduction}

The formation of high-quality multi-look SAR images with airborne SAR systems installed onboard small aircrafts is a difficult problem because of significant motion and orientation errors of such light-weight platforms. Deviations of the aircraft trajectory and instabilities of the antenna orientation lead to geometric and radiometric errors in SAR images [1-3].

Geometric distortions in SAR images can be corrected by interpolation of images to a rectangular grid on the ground plane taking into account the measured aircraft trajectory and orientation of the synthetic aperture beams (SAR beams). However, this approach could be inefficient in the case of significant geometric distortions.

The commonly-used clutter-lock technique [4], which is based on the estimation of the Doppler centroid from radar data, helps prevent radiometric errors very effectively in the case of unknown and slowly-varying antenna orientation. However, the clutter-lock should not be used in the case of fast and significant instabilities of the antenna orientation since it leads to strong geometric errors in SAR images.
Instabilities of aircraft orientation can be compensated by the antenna stabilization. However, it is a complicated and expensive solution. Application of a wide-beam antenna firmly mounted on the aircraft is another way to guarantee the uniform illumination of the ground scene in the central part of the antenna footprint despite of the instabilities of the platform orientation.

In this paper, we describe a time-domain multilook stripmap SAR processing algorithm with built-in correction of geometric distortions. In the algorithm, the azimuth reference functions and range migration curves are specially designed to produce SAR images directly on a correct rectangular grid on the ground plane.

The proposed approach does not use the clutter-lock technique - the synthetic aperture beams do not follow the orientation of the real antenna beam. Therefore, the algorithm works well without an additional radiometric correction only for a widebeam antenna and for central SAR looks, which synthetic beams are directed close to the center of the real antenna beam. In order to produce a multilook SAR image composed of all possible SAR looks, we have proposed an effective radiometric correction technique based on multi-look processing with extended number of looks [5]. 
The proposed method of the built-in geometric correction has been successfully tested by using a Ku-band airborne SAR system [6], installed onboard a light-weight aircraft. First experimental results and brief theoretical description of the method were presented at conferences [7], [8]. This paper describes the method in details.

\section{Formation of Synthetic Aperture in Time Domain}

The geometry of a stripmap SAR mode is shown in Fig. 1. The local coordinate system (xyz) is chosen so that the origin $O$ goes along the projection of the aircraft trajectory onto the ground plane $(x y)$. The $x$-axis is always directed along the current horizontal component of the aircraft velocity vector, viz.

$\overrightarrow{\mathbf{V}}=\left(V_{x}, 0, V_{z}\right)$

The $z$-axis is directed upward and goes through the antenna phase center. $H$ is the current aircraft flight altitude above the ground.

The orientation of the real antenna is described by the antenna pitch angle $\alpha$ and the antenna yaw angle $\beta$. The line $A B$ is the intersection of the elevation plane of the real antenna pattern and the ground plane. This line is called the Doppler centroid line. The coordinates of the point $\left(x_{R}, y_{R}\right)$ on this line at the slant range $R$ are given by

$$
x_{R}=H \tan \alpha \cos \beta+\sin \beta \sqrt{R^{2}-(H / \cos \alpha)^{2}},
$$

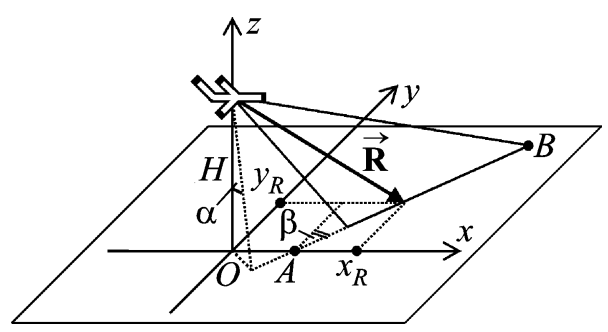

Fig. 1. Geometry of a stripmap SAR mode

$$
y_{R}=-H \tan \alpha \sin \beta+\cos \beta \sqrt{R^{2}-(H / \cos \alpha)^{2}} .
$$

The slant range vector

$$
\overrightarrow{\mathbf{R}}=(x, y,-H)
$$

is directed from the antenna phase center to the point $(x, y)$ on the ground plane at which the synthetic beam should be aimed. In Fig. 1, the synthetic beam is pointed at the center of the real antenna beam, that is at the point $\left(x_{R}, y_{R}\right)$ on the Doppler centroid line (2), (3).

In order to form the synthetic aperture, the received radar pulses should be summed up coherently during the time of synthesis $T_{S}$ taking into account the propagation phase $\varphi(\tau)=$ $-4 \pi R(\tau) / \lambda$, where $R(\tau)$ is the slant range to the target, $\tau$ is the time within the interval of synthesis, $-T_{S} / 2 \leq \tau \leq T_{S} / 2, \quad \lambda$ is the radar wavelength. The formation of the synthetic aperture $I(t)$ ( $t$ is the flight time along the trajectory) can be considered as a matched filtering of the received signal $s(t)$ with the azimuth reference function $h(\tau)$ :

$I(t)=\left|\frac{1}{T_{S}} \int_{-T_{S} / 2}^{T_{S} / 2} s(t+\tau) h(\tau) \mathrm{d} \tau\right|^{2}$,

$h(\tau)=w(\tau) \exp \left[i \frac{4 \pi}{\lambda} R(\tau)\right]$

The weighting window $w(\tau)$ is applied to improve the side-lobe level of the synthetic aperture pattern.

If the slant range $R(\tau)$ to the target changes during the time of synthesis $T_{S}$ more than the size of the range resolution cell, then the target signal "migrates" through several range cells. This effect, known as the range migration, should be taken into account during the aperture synthesis. The one-dimensional backscattered signal $s(t)$, which is convolved with the reference function 
in Eq. (5), should be obtained from the two-dimensional "azimuth - slant range" matrix of the range-compressed radar data by the interpolation along the migration curve:

$R(\tau) \approx R-\frac{\lambda}{2} F_{D C} \tau-\frac{\lambda}{2} F_{D R} \frac{\tau^{2}}{2}$

The Doppler centroid $F_{D C}$ and the Doppler rate $F_{D R}$ are given by

$$
\begin{aligned}
& F_{D C}=\frac{2}{\lambda} \frac{(\overrightarrow{\mathbf{R}} \cdot \overrightarrow{\mathbf{V}})}{R}, \\
& F_{D R}=-\frac{2}{\lambda}\left[\frac{V^{2}}{R}\left(1-\frac{(\overrightarrow{\mathbf{R}} \cdot \overrightarrow{\mathbf{V}})^{2}}{R^{2} V^{2}}\right)-\frac{(\overrightarrow{\mathbf{R}} \cdot \overrightarrow{\mathbf{A}})}{R}\right] .
\end{aligned}
$$

Here $\overrightarrow{\mathbf{A}}$ is the aircraft acceleration vector. Notice here that the aircraft flight altitude, velocity and acceleration, as well as the antenna beam orientation angles are assumed to be constant during the time of synthesis, but may change slowly during longer times.

The azimuth resolution is given by

$$
\rho_{X}=K_{w} \frac{V_{x}}{\Delta F_{D}}=K_{w} \frac{V_{x}}{\left|F_{D R}\right| T_{S}} .
$$

The coefficient $K_{w}$ describes the broadening of the main lobe of the synthetic aperture pattern caused by windowing. The interval of synthesis in time domain $T_{S}$ corresponds to the frequency bandwidth $\Delta F_{D}$ is the azimuth Doppler frequency domain.

It is worth describing here briefly the SAR processing procedure in time domain. The received range-compressed radar data is stored in a memory buffer. The buffer size in range corresponds to the swath width, the buffer size in azimuth is determined by the time of synthesis $T_{S}$. The basic step of the SAR processing procedure for a given range $R$ includes the following calculations:
1) calculation of the Doppler centroid (8), the Doppler rate (9), and the time of synthesis from Eq. (10),

2) interpolation along the migration curve (7),

3) multiplication by the reference function with windowing (6),

4) and, finally, coherent summation (5).

As a result, we obtain one pixel of the SAR image representing the ground point at which the synthetic beam was aimed. This basic step is repeated for all ranges within the swath producing a single line of the SAR image in range direction. In order to form the next line of the SAR image, the data in the buffer is shifted in azimuth and supplemented with new radar data, and the computations are repeated. The new data consists of $K_{S A R}$ radar pulses so that the azimuth sampling interval of the SAR image is

$$
\Delta x_{S A R}=K_{S A R} \frac{V_{x}}{P R F},
$$

where $P R F$ is the radar pulse repetition frequency.

The described time-domain SAR processing is a streaming processing which forms SAR images line-by-line. It is different from the framebased SAR processing algorithms [9] which use the fast Fourier transform (FFT) and work in frequency domain, forming a SAR image frame immediately. Prior to the usage of any of FFT-based algorithms, one should apply motion compensation to the received radar data [10], [11] in order to compensate deviations of the aircraft trajectory from a straight line. The problem is that the motion compensation and the conventional FFT-based processing cannot be used in the case of significant deviations from the reference flight line. Alternative SAR processing algorithms for imaging from curvilinear trajectories are considered in [12]. Running ahead we should say that the algorithm of the built-in geometric correction proposed in this paper belongs to streaming algorithms and works despite significant motion errors.

The described SAR algorithm is effective for building moderate-resolution SAR images when the convolution is not too long. The advantage of the algorithm is its ability to build each pixel of the SAR image with a particular reference 
function and migration curve, in contrast to the FFT-based SAR algorithms. It means that the algorithm works well for time-varying and rangedependent Doppler centroid and Doppler rate, which is the case of SAR systems installed on small aircrafts.

\section{Multi-Look Processing in Time Domain}

Multi-look processing is implemented in most modern SAR systems. According to this technique, several SAR images of the same ground scene, called SAR looks, are produced from the radar data collected on conjugated segments of the aircraft trajectory. To suppress speckle noise, the SAR look images are summed up non-coherently resulting in a multi-look SAR image of higher quality [1], [13]. Multi-look imaging is also used for other applications, for example, for measuring the Doppler centroid with high accuracy and high spatial resolution [14].

The multi-look processing in time domain is usually performed directly following the definition, as illustrated in Fig. 2(a) and Fig. 3(a). Namely, the reference functions and range migration curves are built for the long interval of synthesis $T_{S \max }$, which is the time required for the ground target to cross the antenna footprint. The multi-look processing is performed by splitting the long interval $T_{S \text { max }}$ of the coherent summation (5) on several integrals on sub-intervals $T_{S}$, thus forming the multiple synthetic beams pointed to the same point on the ground. The number of looks for a scheme with half-overlapped sub-intervals is given by

$N_{L}=\operatorname{int}\left\{\frac{T_{S \max }}{T_{S} / 2}\right\}-1$.

It will be observed that in the case of many looks, the interval of synthesis $T_{S \max }$ could become so long that the quadratic approximation of the slant range law (7) will be inaccurate, and we should use a cubic approximation or the precise square-root law for the slant range instead.

In order to use the described time-domain multilook processing approach successfully, we should guarantee that there are no significant uncompen-
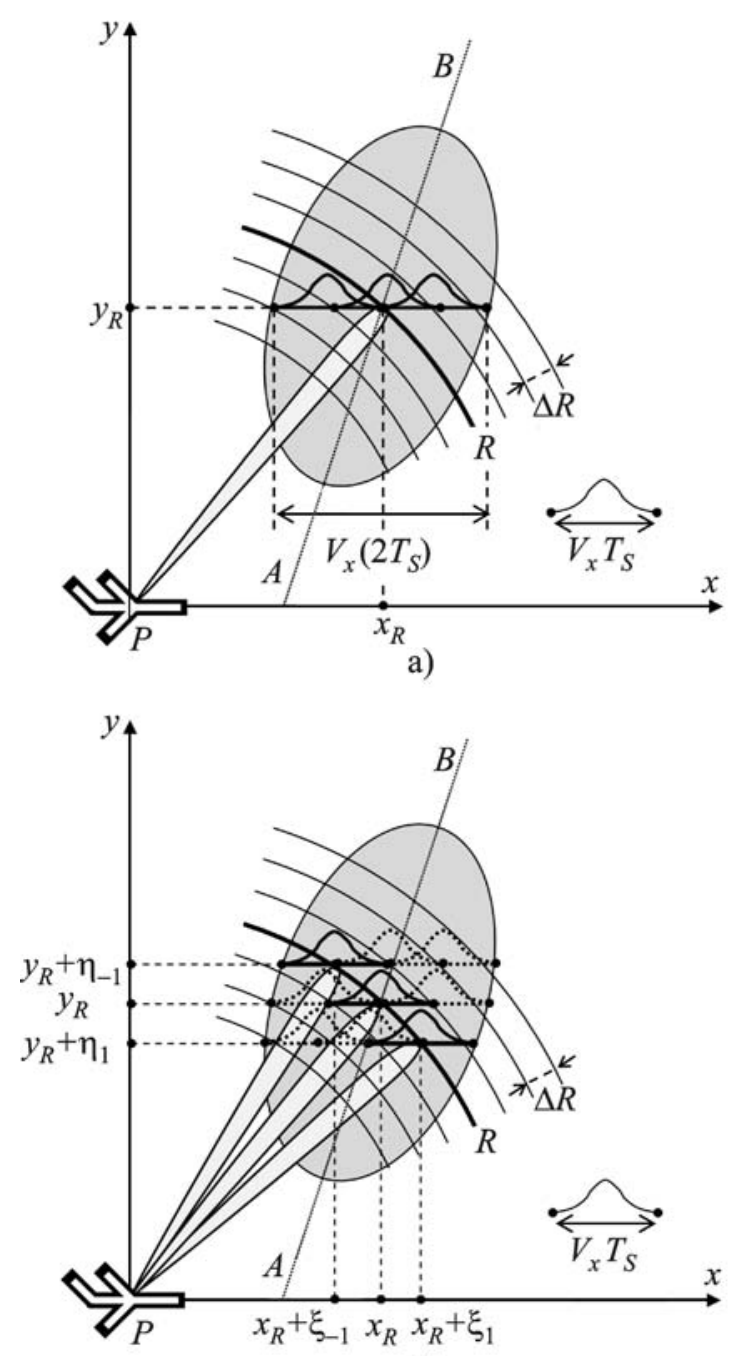

b)

Fig. 2. The conventional multi-look processing (a) and the multi-look processing on a single-look interval of synthesis (b): the antenna footprint consideration

sated phase errors during the long coherent processing time. However, as a matter of fact, in order to achieve the desired azimuth resolution for one SAR look it is sufficient to perform coherent processing on the short time interval $T_{S}$ according to Eq. (10). This consideration turns us to another approach, which is more preferable in the case of significant motion errors. The idea is to process the data collected during the short time of synthesis $T_{S}$ with a set of different reference functions and migration curves to form multilook SAR beams. We have called this approach 


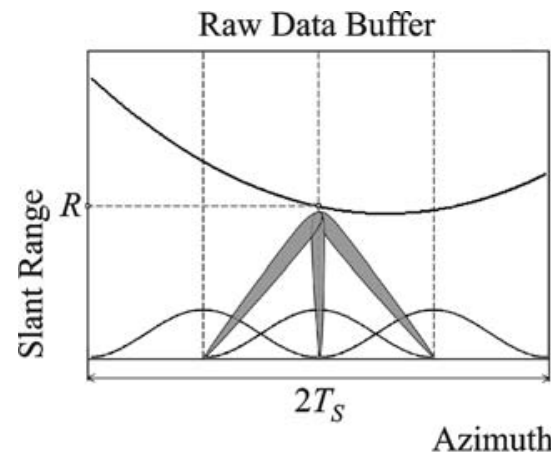

(a)

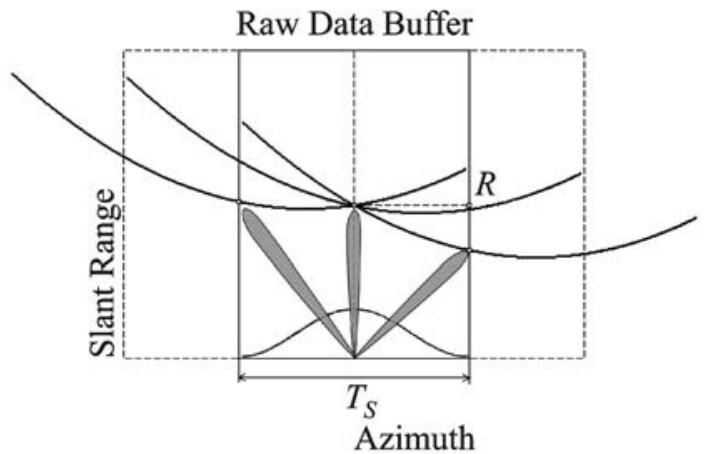

(b)

Fig. 3. The conventional multi-look processing (a) and the multi-look processing on a single-look interval of synthesis (b): the raw data buffer consideration

"the multi-look processing on a single-look interval of synthesis". The question is how to build these reference functions. The answer can be obtained from the consideration of central frequencies of SAR looks.

Considering the multi-look processing we may say that the splitting of a long interval of synthesis on several sub-intervals for coherent summation in time domain corresponds to the dividing of the whole azimuth Doppler bandwidth

$$
\Delta F_{D \max }=\left|F_{D R}\right| T_{S \max }
$$

on several sub-bands in frequency domain for separate matched filtering. For multi-look processing scheme with the half-overlapped subbands (12), the central frequencies and the width of the sub-bands are given by

$F_{C}\left(R, n_{L}\right)=F_{D C}(R)-n_{L} \frac{\Delta F_{D}}{2}$,

$\Delta F_{D}=\frac{\Delta F_{D \max }}{\left(N_{L}+1\right) / 2}$,

where $n_{L}=-N_{L} / 2, \ldots, N_{L} / 2-1$ is the SAR look index. The SAR look sub-intervals are numerated from left to right both in time and in frequency domains. However, since the Doppler rate is al- ways negative (9), the first sub-interval in time domain corresponds to the last sub-interval in frequency domain. Therefore, we write the "minus" sign in Eq. (14) in order to use the same "leftright" SAR look index in both domains, for convenience.

Taking into account the relation (10) for the azimuth resolution and Eqs. (13), (15), the central frequencies of the SAR looks (14) can be written as

$\Delta F_{C}\left(R, n_{L}\right)=F_{D C}(R)-n_{L} \frac{K_{w}}{2} \frac{V_{x}}{\rho_{X}}$.

Thus, we should process the same radar data on the short interval of synthesis $T_{S}$ with a set of different reference functions, which central Doppler frequencies are given by the relation (16).

The proposed approach is illustrated in Fig. 2(b) and Fig. 3(b). According to the principle of SAR processing in time domain, in order to aim the SAR beam at any particular point $(x, y)$ we should perform processing with the corresponding range migration curve (7), the Doppler centroid $F_{D C}(R)(8)$, and the Doppler rate $F_{D C}(R)$ (9). Considering in backward direction, the SAR look beam formed with the central frequencies $\Delta F_{C}\left(R, n_{L}\right)(16)$ will be pointed to some points $\left(x_{R}+\xi\left(R, n_{L}\right), y_{R}+\eta\left(R, n_{L}\right)\right)$ which appear at the same slant range $R$ at the center of the interval of synthesis (see Fig. 2(b) and Fig. 3(b)). Let us find the coordinates of these points. 
First, since the signals from these points have appeared at the slant range $R$ when the aircraft is at the center of the synthetic aperture, we can write

$$
\begin{aligned}
& \sqrt{x_{R}^{2}+y_{R}^{2}+H^{2}} \\
& =\sqrt{\left(x_{R}+\xi\left(R, n_{L}\right)\right)^{2}+\left(y_{R}+\eta\left(R, n_{L}\right)\right)^{2}+H^{2}},
\end{aligned}
$$

$x_{R}^{2}+y_{R}^{2}=\left(x_{R}+\xi\left(R, n_{L}\right)\right)^{2}+\left(y_{R}+\eta\left(R, n_{L}\right)\right)^{2}$.

Second, the position of the point in the azimuth direction is related to its Doppler centroid (8), so we can write

$\Delta F_{C}\left(R, n_{L}\right)=\frac{2}{\lambda} \frac{\left(x_{R}+\xi\left(R, n_{L}\right)\right) V_{x}-H V_{z}}{R}$.

Substituting the relation (16) in Eq. (18), we obtain

$F_{D C}(R)-n_{L} \frac{K_{w}}{2} \frac{V_{x}}{\rho_{X}}=\frac{2}{\lambda} \frac{\left(x_{R}+\xi\left(R, n_{L}\right)\right) V_{x}-H V_{z}}{R}$,

$\xi\left(R, n_{L}\right)=-n_{L} \frac{K_{w} \lambda}{4 \rho_{X}} R$

Now, we can calculate the coordinate $\eta\left(R, n_{L}\right)$ from Eq. (17) as

$\eta\left(R, n_{L}\right)=\sqrt{x_{R}^{2}+y_{R}^{2}-\left(x_{R}+\xi\left(R, n_{L}\right)\right)^{2}}-y_{R}$.

Thus, in order to form the set of SAR looks for the slant range $R$ with central frequencies (16) we should first calculate the corresponding points $\left(x_{R}+\xi\left(R, n_{L}\right), y_{R}+\eta\left(R, n_{L}\right)\right)$ on the ground from Eq. (19) and Eq. (20) and then process the same raw data on the interval of synthesis $T_{S}$ with the appropriate range migration curves (7), Doppler centroids (8) and Doppler rates (9).

It will be observed that all SAR look beams are aimed at different points on the ground.
It means that the obtained SAR look images are sampled on different grids. Therefore, the SAR look images should be first re-sampled to the same ground grid and only then they can be averaged to produce the multi-look image. The deviations of the aircraft trajectory introduce further complexity into the re-sampling process. An efficient approach to solve this problem called "built-in correction of geometric distortions" is proposed in the next section.

\section{Built-In Correction of Geometric Distortions}

In order to perform the multi-look processing on a single-look interval of synthesis and, at the same time, to avoid complicated re-sampling of the SAR look images to the rectangular grid (including the correction of geometric errors), we have proposed an algorithm of "built-in correction of geometric distortions". The idea of the built-in geometric correction is to point the multilook SAR beams exactly to the nodes of the rectangular grid on the ground plane as early as at the stage of synthesis. In this way, we immediately obtain geometrically correct SAR look images and avoid the interpolation post-processing step.

In order to define the rectangular grid on the ground plane, we should determine the following reference (constant) parameters: the reference flight direction, the reference aircraft flight altitude $H_{0}$ and velocity $V_{0}$, the reference orientation of the antenna beam with the antenna pitch and yaw angles $\alpha_{0}$ and $\beta_{0}$, as well as the reference pulse repetition period $T_{0}$. These parameters determine the reference flight line which is close to the actual curvilinear flight trajectory of the aircraft.

We shall define the scene coordinate system $(X, Y, Z)$ so that the reference flight line goes exactly above the $X$ axis. The rectangular grid for SAR processing is the coordinate grid of the ground plane $(X, Y)$. The scene coordinate system is shown in Fig. 4 together with the actual local coordinate system $(x, y, z)$, which slides along the real aircraft flight trajectory, and the reference local coordinate system $\left(x_{\text {ref }}, y_{\text {ref }}, z_{\text {ref }}\right)$, which slides along the reference flight line, that is along the $X$ axis. The current flight direction 


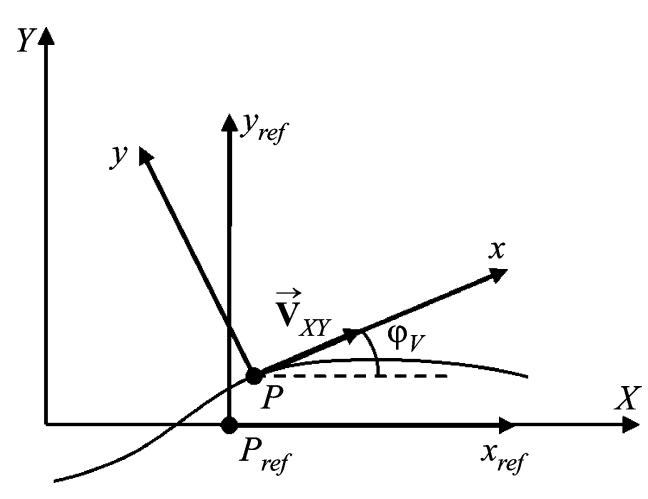

Fig. 4. The scene coordinate system, the reference local coordinate system, and the actual local coordinate system

is described by the angle $\varphi_{V}$ between the horizontal component of the velocity vector $\overrightarrow{\mathbf{V}}_{X Y}$ and the $X$ axis. The coordinates $(x, y)$ are related to the coordinates $\left(x_{r e f}, y_{\text {ref }}\right)$ as follows

$$
\begin{aligned}
& x=\left[x_{r e f}-X_{A}(t)+V_{0} t\right] \cos \varphi_{V}(t) \\
& +\left[y_{\text {ref }}-Y_{A}(t)\right] \sin \varphi_{V}(t), \\
& y=-\left[x_{r e f}-X_{A}(t)+V_{0} t\right] \sin \varphi_{V}(t) \\
& +\left[y_{r e f}-Y_{A}(t)\right] \cos \varphi_{V}(t) .
\end{aligned}
$$

Notice here that formulas (1)-(4) of the described time-domain SAR processing algorithm and formulas (19), (20) of the multi-look processing are valid with respect to the actual local coordinate system. It means that in order to aim the synthetic beam at a point with the scene coordinates $(X, Y)$ or the reference local coordinates $\left(x_{\text {ref }}, y_{\text {ref }}\right)$ we should calculate the corresponding actual local coordinates $(x, y)(21),(22)$ of this point to use them in calculation of the Doppler centroid (8), the Doppler rate (9) and the migration curve (7). For the aircraft velocity we have simply $V_{x}=V_{X Y}$ and $V_{z}=V_{Z}$. The aircraft position and velocity vector are measured with a simple GPS receiver.

There are several important requirements for the grid steps in azimuth and ground range direc- tions, $\Delta x_{G}$ and $\Delta y_{G}$. The first one is that the grid steps should be smaller than the corresponding resolutions just to have at least one image sample per resolution cell:

$\Delta x_{G}=\rho_{X} / k_{X}, \quad k_{X} \geq 1 ; \quad \Delta y_{G}=\rho_{R} / k_{Y}, \quad k_{Y} \geq 1$.

Typically, the sampling factors $k_{X}$ and $k_{Y}$ are approximately equal to 2 (two samples per resolution cell). Also, it is convenient to choose the same grid step in azimuth and in ground range, $\Delta x_{G} \approx \Delta y_{G}$.

The second requirement to the grid step in azimuth comes from peculiarities of the timedomain SAR processing algorithm. As aforesaid, when we move from the one step of synthesis to the next step, we update the radar data buffer with $K_{S A R}$ new pulses (11). The grid step in azimuth should be equal exactly to this number of pulses, viz.

$\Delta x_{G}=\Delta x_{S A R}=K_{S A R}\left(V_{0} T_{0}\right)$.

The grid nodes to which the multi-look SAR beams should be pointed can be found as follows. The reference parameters are used to calculate the Doppler centroid values $F_{D C}(R)$, the central Doppler frequencies $F_{C}\left(R, n_{L}\right)$ of the SAR looks, and the coordinates of the corresponding points on the ground in the reference local coordinate system, viz.

$$
\begin{aligned}
& \left\{x_{\text {ref }}\left(n_{R}, n_{L}\right), y_{\text {ref }}\left(n_{R}, n_{L}\right)\right\}, \\
& \left\{x_{R}\left(R_{n_{R}}\right)+\xi\left(R_{n_{R}}, n_{L}\right), y_{R}+\eta\left(R_{n_{R}}, n_{L}\right)\right\} .
\end{aligned}
$$

These computations are performed for all range gates, $R_{n_{R}}=R_{0}+n_{R} \Delta R, \quad n_{R}=0,1, \ldots, N_{R}-1$ is the slant range gate index, $N_{R}$ the number of the range gates within the swath, $R_{0}$ the near slant range of the swath, and $\Delta R$ the slant range sampling interval. The found points are shown in Fig. 5 by circles and are situated on the central frequency lines which are similar to the Doppler 


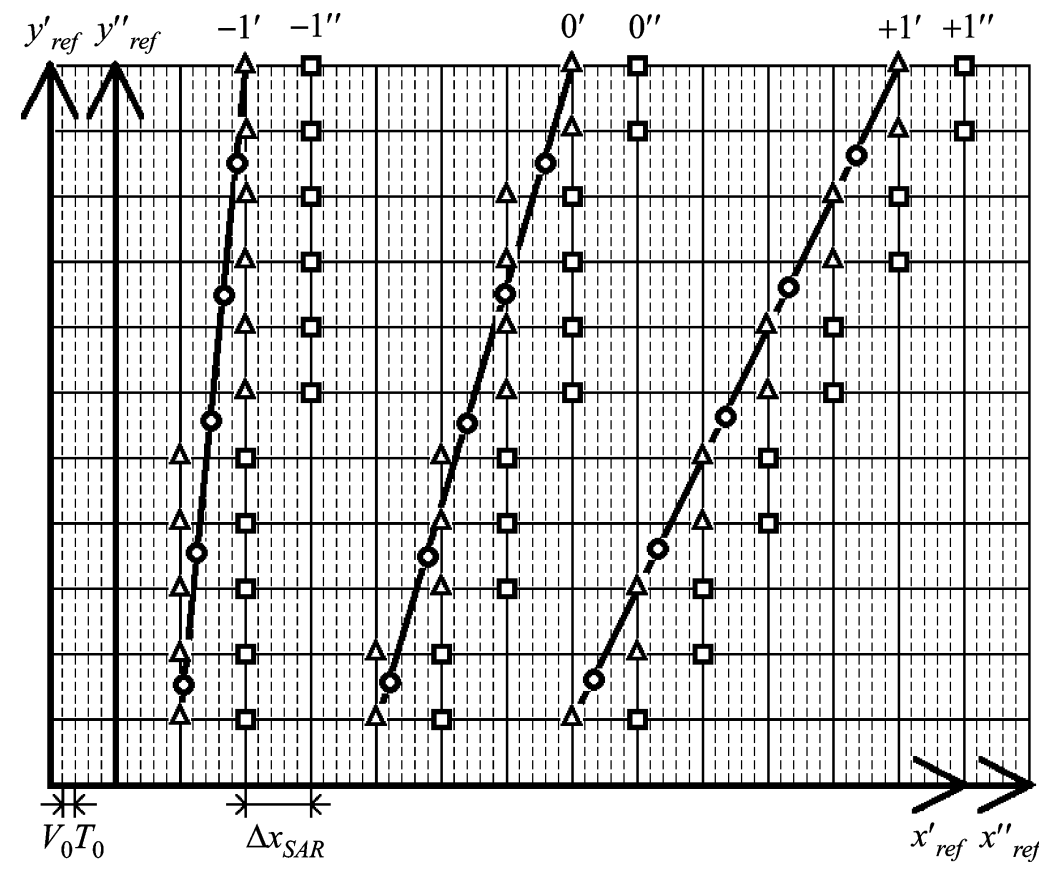

Fig. 5. Grid nodes in the built-in geometric correction algorithm

centroid line $A B$ in Fig. 1. By using interpolation, we find the points situated on the ground-range grid lines

$\left\{x_{\text {ref }}\left(n_{Y}, n_{L}\right), y_{\text {ref }}^{\text {node }}\left(n_{Y}, n_{L}\right)\right\}$,

$y_{\text {ref }}^{\text {node }}\left(n_{Y}, n_{L}\right)=y_{0}+n_{Y} \Delta y_{G}$.

Here $n_{Y}$ is the ground range index of the grid, $y_{0}$ the near ground range of the swath. Finally, rounding the $x$-coordinates, we find the closest nodes of the grid,

$\left\{x_{\text {ref }}^{\text {node }}\left(n_{Y}, n_{L}\right), y_{\text {ref }}^{\text {node }}\left(n_{Y}, n_{L}\right)\right\}$,

$x_{\text {ref }}^{\text {node }}\left(n_{Y}, n_{L}\right)=\operatorname{round}\left[x_{\text {ref }}\left(n_{Y}, n_{L}\right)\right]$,

indicated by triangles in Fig. 5 .

Here the third requirement to the grid step in azimuth arises. If the coordinates of the nodes of the adjacent looks $x_{\text {ref }}^{\text {node }}\left(n_{Y}, n_{L}\right)$ and $x_{\text {ref }}^{\text {node }}\left(n_{Y}, n_{L}+1\right)$ are closer than the grid step $\Delta x_{G}$, these nodes will coincide. To prevent such a situation we should decrease the grid step $\Delta x_{G}$ and, consequently, increase the sampling factor $k_{X}$ (23) so that

$\left|x_{\text {ref }}^{\text {node }}\left(n_{Y}, n_{L}+1\right)-x_{\text {ref }}^{\text {node }}\left(n_{Y}, n_{L}\right)\right| \geq \Delta x_{G}$.

Thus, the grid steps should satisfy the requirements (23), (24) and (25).

Moving from the one step of synthesis to the next step, the data buffer is updated with $K_{S A R}$ new radar data pulses $\left(K_{S A R}=5\right.$ in Fig. 5), we move up to the next reference local coordinate system, from $\left(x_{r e f}^{\prime}, y_{r e f}^{\prime}\right)$ to $\left(x_{r e f}^{\prime \prime}, y_{r e f}^{\prime \prime}\right)$, and the next neighbor grid nodes indicated by squares in Fig. 5 are used for pointing the SAR look beams.

In order to point the SAR look beams to particular grid nodes, we should recalculate the coordinates of these nodes from the reference local coordinate system to the actual local coordinate system by using Eqs. (21), (22), taking into account the actual aircraft position and orientation of the aircraft velocity vector. This recalculation 
is performed at each step of the synthesis. Thus, we obtain geometrically-correct SAR image sampled at the grid nodes of a rectangular grid on the ground plane.

The proposed built-in geometric correction algorithm cannot be combined with the clutterlock technique - the SAR beams do not follow the orientation of the real antenna beam. Therefore, the algorithm works well without additional radiometric correction only for a wide-beam antenna and only for the central SAR looks. In order to use all possible SAR looks to form the multilook SAR image without radiometric errors, we have proposed an effective radiometric correction technique based on multi-look processing with extended number of looks [5].

\section{Results}

The geometric correction is illustrated in Fig. 6. The SAR image shown in Fig. 6(a) was built by using the clutter-lock technique. One can see the geometric distortions caused by instabilities of antenna orientation. The correct SAR image shown in Fig. 6(b) was formed by using the algorithm with the built-in geometric correction. Both images have 3-m resolution and were built using 3 looks.

The accuracy of the geometric correction is illustrated in Fig. 7, where the SAR image composed of 45 looks and formed by using the builtin geometric correction is imposed on the Google Map image of the scene. One can see that the SAR processing algorithm with the built-in correction of geometric distortions proposed in this paper allows building high-quality multi-look SAR images.

The obtained results prove that the proposed algorithm can be effectively used for a SAR system installed onboard a light-weight aircraft with a non-stabilized antenna. An important advantage of the algorithm is that the produced SAR images are already geometrically correct immediately after synthesis, and there is no need in any additional interpolation. Another important advantage of the algorithm is the reduced requirements for the SAR navigation system. Although the aircraft velocity vector should be measured quite accurately to aim the synthetic

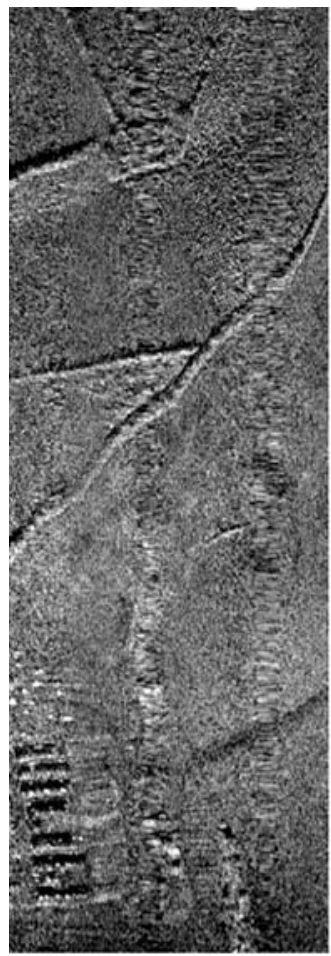

(a)

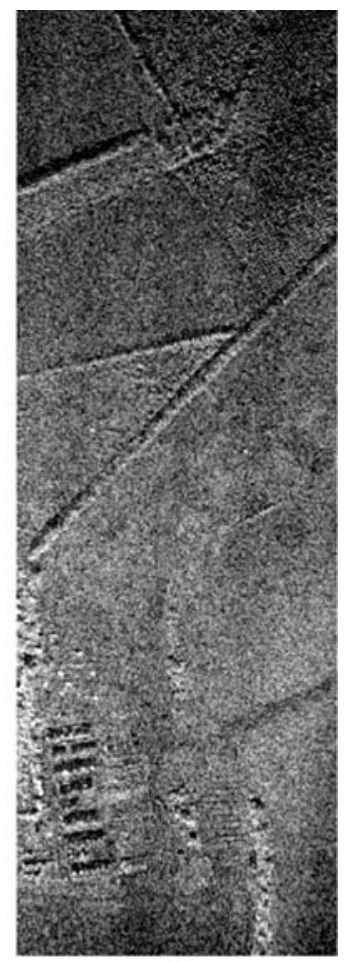

(b)
Fig. 6. Illustration of geometric correction: a 3-look SAR image built by using the clutter-lock technique (a), and a 3-look SAR image formed by using the builtin geometric correction (b)

beams at proper points on the ground, the aircraft trajectory should be measured and compensated with the high accuracy of a fraction of the radar wavelength only during the short time of synthesis of one look. There is no need to keep so high accuracy during the long time of data acquisition for all looks. In order to combine all SAR looks into one multi-look image, it is sufficient to measure the trajectory with the accuracy of a fraction of the SAR resolution.

The algorithm requires lots of computations in the case of SAR imaging with very high resolution because of the long time-domain convolution, and this is its disadvantage. Other SAR processing methods could be more efficient in computations, however the SAR system must be equipped with a stabilized antenna and good navigation system, and full motion error compensation should be performed, too. 


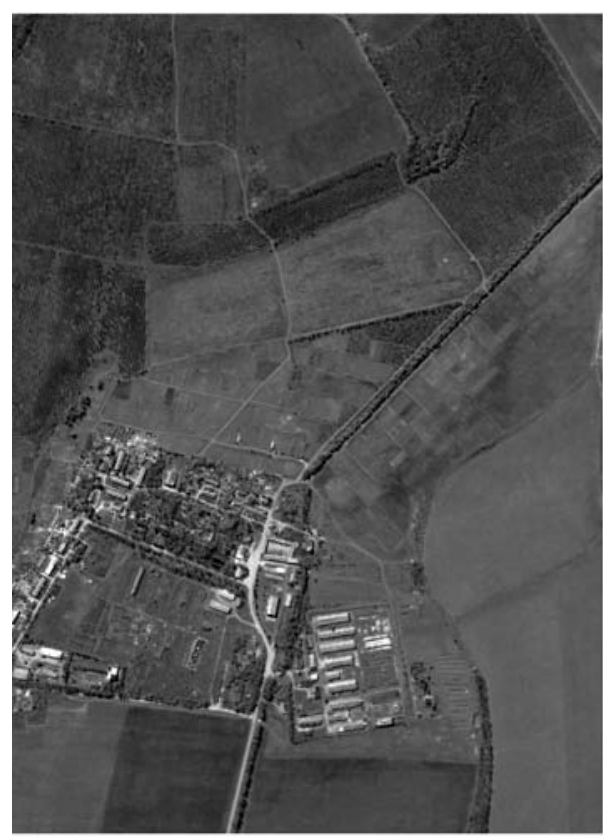

(a)

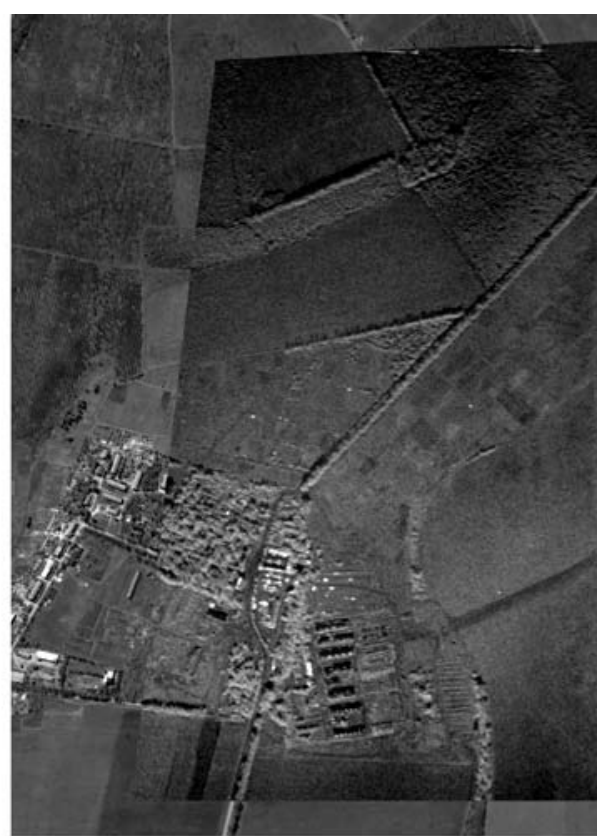

(b)

Fig. 7. A 45-look SAR image formed by using the built-in geometric correction (a) is imposed on the Google Maps image of the scene (b)

\section{References}

1. C. J. Oliver, and S. Quegan, Understanding Synthetic Aperture Radar Images, SciTech Publishing, 2004, 464 p. 2. S. Buckreuss, "Motion errors in an airborne synthetic aperture radar system", Eur. Trans. Telecomm., vol. 2, no. 6, pp. 655-664, 1991.

3. D. Blacknell, A. Freeman, S. Quegan, I. A. Ward, I. P. Finley, C. J. Oliver, R. G. White, and J. W. Wood, "Geometric accuracy in airborne SAR images", IEEE Trans. Aerospace Electronic Systems, vol. 25, no. 2, pp. 241-258, 1989.

4. S. N. Madsen, "Estimating the Doppler centroid of SAR data", IEEE Trans. Aerospace Electronic Systems, vol. 25, no. 2, pp. 134-140, 1989.

5. O. O. Bezvesilniy, I. M. Gorovyi, V. V. Vinogradov, and D. M. Vavriv, "Correction of radiometric errors by multi-look processing with extended number of looks", in Proc. 11th International Radar Symposium IRS 2010 (Vilnius, Lithuania), 2010, vol. 1, pp. 26-29.

6. D. M. Vavriv, V. V. Vynogradov, V. A. Volkov, R. V. Kozhyn, O. O. Bezvesilniy, S. V. Alekseenkov, A. V. Shevchenko, A. A. Belikov, M. P. Vasilevskiy, and D. I. Zaikin, "Cost-effective airborne SAR", Radiofizika i Radioastronomia, vol. 11, no. 3, pp. 276-297, 2006.

7. O. O. Bezvesilniy, I. M. Gorovyi, S. V. Sosnytskiy, V. V. Vinogradov, and D. M. Vavriv, "Multi-look stripmap SAR processing algorithm with built-in correction of geometric distortions", in Proc. 8th European Conference on Synthetic Aperture Radar EUSAR2010 (Aachen, Germany), 2010, pp. 712-715.

8. O. O. Bezvesilniy, I. M. Gorovyi, S. V. Sosnytskiy, V. V. Vinogradov, and D. M. Vavriv, "Multi-look SAR processing with build-in geometric correction", in Proc. 11th International Radar Symposium IRS2010 (Vilnius, Lithuania), 2010, vol. 1, pp. 30-33.

9. I. G. Cumming, and F. H. Wong, Digital Processing of Synthetic Aperture Radar Data: Algorithms and Implementation. Norwood, MA: Artech House, 2005, 625 p. 10. M. Soumekh, Synthetic Aperture Radar Signal Processing with MATLAB Algorithms. New York, NY: Wiley-Interscience, 1999, 648 p.

11. G. Franceschetti, and R. Lanari, Synthetic Aperture Radar Processing. Boka Raton, FL: CRC Press, 1999, 328 p. 12. O. Frey, C. Magnard, M. Rüegg, and E. Meier, "Focusing of airborne synthetic aperture radar data from highly nonlinear flight tracks", IEEE Trans. Geosci. Remote Sensing, vol. 47, no. 6, pp. 1844-1858, 2009. 13. A. Moreira, "Improved multilook techniques applied to SAR and SCANSAR imagery", IEEE Trans. Geosci. Remote Sensing, vol. 29, no. 4, pp. 529-534, July 1991. 14. O. O. Bezvesilniy, I. V. Dukhopelnykova, V. V. Vinogradov, and D. M. Vavriv, "Retrieving 3-D topography by using a single-antenna squint-mode airborne SAR", IEEE Trans. Geosci. Remote Sensing, vol. 45, no. 11, pp. 3574-3582, 2007. 


\section{Алгоритм со встроенной геометрической коррекцией для обработки данных РСА}

\section{А. А. Безвесильный, Е. Н. Горовой, С. В. Сосницкий, В. В. Виноградов, Д. М. Ваврив}

Радиолокационные системы с синтезированной апертурой (РСА), установленные на небольших самолетах, подвержены влиянию отклонений траектории и нестабильности ориентации антенны. Такие ошибки движения приводят к значительным геометрическим искажениям на радиолокационных изображениях (РЛИ). Чтобы исправить эти искажения, мы предлагаем алгоритм многовзглядовой обработки со встроенной геометрической коррекцией, работающий во временной области и предназначенный для РСА бокового обзора. В этом алгоритме азимутальные опорные функции и кривые миграции строятся таким образом, чтобы получать РЛИ сразу на прямоугольной сетке в плоскости земли. Предложенный метод был успешно испытан с использованием самолетного РСА сантиметрового диапазона длин волн, установленного на легком самолете.

\section{Алгоритм з вбудованою геометричною корекцією для обробки даних РСА}

\author{
О. О. Безвесільний, Є. М. Горовий, \\ С. В. Сосницький, В. В. Виноградов, \\ Д. М. Ваврів
}

Радіолокаційні системи 3 синтезованою апертурою (РСА), встановлені на невеликих літаках, зазнають впливу відхилень траєкторії і нестабільності орієнтації антени. Такі помилки руху призводять до значних геометричних спотворень на радіолокаційних зображеннях (РЛЗ). Аби виправити ці спотворення, ми пропонуємо алгоритм багатопоглядової обробки 3 вбудованою геометричною корекцією, який працює у часовому просторі та призначений для РСА бічного огляду. У цьому алгоритмі азимутальні опорні функції та криві міграції формуються таким чином, щоб отримувати РЛ3 одразу на прямокутній сітці в площині землі. Запропонований метод було успішно випробувано з використанням РСА сантиметрового діапазону довжин хвиль, встановленому на легкому літаку. 